\title{
Исследование структурной неоднородности олигомеров методами двухдетекторной высокоэффективной жидкостной хроматографии
}

\author{
Бекташи Н.P. \\ Институт полимерных материалов НАН Азербайджана, Сумгайыт \\ Поступила в редакцию 17.07.2017 г.
}

\begin{abstract}
В статье представлен краткий обзор работ, посвященных исследованию различных типов неоднородности макромолекул в разных полимерных системах, методом двухдетекторной жидкостной хроматографии. Рассмотрены различные аспекты реакции аминирования $\alpha$-гексена методами двухдетекторной адсорбционной и эксклюзионной ВЭЖХ, а также результаты динамических изменений состава и структуры продуктов аминирования. Показано, что в составе полученных продуктов кроме целевых индивидуальных аминов обнаруживаются олигомеры, молекулярные массы которых меняются в пределах $M_{n}=460-800$. Методом двухдетекторной обращено-фазовой адсорбционной хроматографии в составе олигомеров кроме разделения по молекулярной массе было установлено также разделение по изомерному составу. Химическими и спектроскопическими методами изучены составы и структура синтезированных продуктов.
\end{abstract}

Ключевые слова: изомеры, молекулярно-массовое распределение, олигомеры, структурная неоднородность, эксклюзионная жидкостная хроматография

\section{Investigation of structural homogeneity of oligomers by a method of two-detector high effective liquid chromatography}

\author{
Bektashi N.R. \\ Institute of Polymer Materials of Azerbaijan National Academy of Sciences, Sumgait
}

In this work it has been presented a short review of works devoted to the investigation of various types of heterogeneity of macromolecules in the various polymer systems by a method of two-detector liquid chromatography. It has been shown based on results of analysis of literary sources that practically there is no information about division of polymers on isomer composition. The aim of this work consists in study of the structural heterogeneity of amination products of $\alpha$-hexene in the synthesized redox system $\mathrm{NH}_{2} \mathrm{OH} \cdot \mathrm{HCl}-$ $\mathrm{TiCl}_{3}$ and in revealing by the methods of two-detector exclusion and reversed-phase HPLC of possible types of division on chemical composition of products. The results of the investigations of amination reaction of hexene by the methods of two-detector adsorption and exclusion HPLC and observations for dynamics of change of composition and structure of the amination products have been presented. It has been shown that in the composition of the prepared products besides purposeful individual amines the oligomers, molecularweights changing approximately within the limits of $M_{n}=460-800$ are detected. By a method of two-detector reversed-phase adsorption chromatography in composition of oligomers, besides division on molecular weight it has been also established the division on isomer composition, a formation of which occurs during migration to various carbon atoms. So it has been noted that at refractometric detection a division is observed only on molecular weight, and in a case of UV-detector in adsorption regime a division of fraction is also fixed on isomer composition. It has been concluded on multiplicity that in the investigated process during proton migration to various carbon atoms it occurs a formation of radicals with various reactivity; hereupon 
the oligomers with various molecular weights are respectively formed. The structure of amination products has been studied and confirmed by the methods of IR- and NMR-spectroscopy.

Keywords: isomers, molecular-weight distribution, oligomers, structural homogeneity, exclusion liquid chromatography

\section{Введение}

В развитии современной физико-химии полимеров особое внимание уделяют вопросам повышения качества полимеров, получения материалов с заранее заданными свойствами. В связи с этим при характеристике полимера важное значение имеет наличие информации о его молекулярно-массовой (ММ) и структурной неоднородности. Метод гель-проникающей хроматографии (ГПХ) стал первым инструментальным методом определения молекулярно-массового распределения (ММР) синтетических и природных полимеров. Многие работы в этом направлении стали появляться, особенно, в 1970-е годы [1-7]. Следует отметить, что в этих и многих других работах разделение полимеров выполнялись лишь по ММ.

Изучение структурной неоднородности полимеров не исчерпывается только определением ММР. Она включает в себя также неоднородность по числу и типу концевых функциональных групп - распределение по типам функциональности (РТФ), по топологической структуре, т.е по структуре макроцепи (наличие линейных, разветвленных и циклических макромолекул) и т.д. [8-10]. Большим прогрессом в исследовании полимеров стало появление высокоэффективной жидкостной хроматографии (ВЭЖХ). В настоящее время при анализе структурных неоднородностей полимерных веществ, применяют многодетекторную ВЭЖХ включающую в себя различные хроматографические системы (эксклюзионная, адсорбционная и критическая хроматография). Необходимо отметить, что комплексное применение указанных методов (многомерная хроматография) позволяет получить гораздо больше информации о структурной неоднородности полимеров.

Работа [11] посвящена исследованию РТФ макромономеров с полиэтиленоксидными и полипропиленоксидными цепями методом ВЭЖХ при разделении в критических условиях на нормальной и обращенной фазах. Показано, что комбинация трех разных групп на концах цепи дает шесть возможных типов функциональности макромолекул: $\mathrm{CH}_{2}=\mathrm{CH}, \mathrm{OCH}_{3}, \mathrm{CH}_{2}=\mathrm{CHOH}, \mathrm{CH}_{2}=\mathrm{CH}, \mathrm{CH}=\mathrm{CH}_{2}$ и $\mathrm{HO}-\mathrm{OH}$. Аналогичную картину наблюдали для макромономеров полипропиленоксида, где вместо

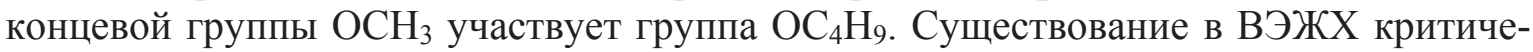
ской области на границе адсорбционного и эксклюзионного режимов разделения, в которой практически исчезает деление макромолекул по ММ, позволяет на фоне исчезновения деления по размерам получить информацию исключительно о РТФ исследуемых образцов [12].

Рассмотрены возможности [13] метода критической хроматографии макромолекул, дополненного методом масс-спектрометрии, для исследования наиболее сложной характеристики строения макромолекулы - определения места дефектного звена или функциональной группы в последовательности звеньев цепи. В качестве объектов исследования использованы образцы полиуретанов на основе олигомеров полипропиленоксида. Предложена модель разделения пептидов, основанная на методе критической хроматографии макромолекул [14]. Модель применена для оценки возможности разделения в разных хроматографических режимах пептидов с одинаковым аминокислотным составом, различающихся последовательностью расположения звеньев в цепи, а также содержащих изомеры аминокислот, зеркальные последовательности с разными концевыми группами.

Бекташи Н.P. / Сорбционные и хроматографические процессы. 2018. Т. 18. № 1 
Методами двухдетекторной эксклюзионной ВЭЖХ и критической хроматографии в составе продуктов олигомеризации эпихлоргидрина были обнаружены пять типов бифункциональных макромолекул с разными концевыми группами и параметрами ММР $[15,16]$. В работах $[17,18]$ с помощью методов эксклюзионной (ЭЖХ) и нормально-фазовой адсорбционной жидкостной (АЖХ) хроматографии в составе вторичных низкомолекулярных продуктов производства ПЭВД помимо с неоднородностями по ММР и РТФ зафиксирована неоднородность по топологии макромолекул, и в составе исследуемых продуктов обнаружены линейные и разветвленные олигомерные цепи.

Двухдетекторной ЭЖХ изучена динамика изменения молекулярной структуры и функциональности полимерных пленок на основе ПЭВД при эксплуатации в природных условиях [19]. Показано, что в результате воздействия деструктурирующих природных факторов в составе полимерных пленок образуется серия низкомолекулярных фракций и функциональные $\mathrm{C}=\mathrm{C}$ - связи и $\mathrm{C}=\mathrm{O}$ группы.

Работа [20] посвящена исследованию многостадийного процесса синтеза и особенностей молекулярной структуры полифункциональных эписулфидсодержащих полимерных комплексов на основе аминов и тиокарбамида.

Метод двухдетекторной ЭЖХ применен также в работе [21] с целью изучения закономерностей образования продуктов реакции поликонденсации ангидрида норборнендикарбоновой кислоты с этиленгликолем и метакриловой кислотой. В составе исследуемых продуктов были обнаружены шесть типов бифункциональных макромолекул, а также молекулы индивидуальных аддуктов, образующиеся при различных комбинациях исходных соединений.

В работе [22] комплексным использованием двухдетекторной ЭЖХ и обращенно-фазовой АЖХ исследовано ММР и функциональные составы полученных в процессе биосинтеза полисахаридов и полиацетиленов, источниками которых являлись базидиомицеты рода Ganoderma lucidum и Pleurotus ostreatus. При этом в составе продуктов биосинтеза выделены и идентифицированы четыре фракции полисахаридов с разными параметрами ММР и пять фракций полиацетиленовых соединений с сопряженными ненасыщенными связями различной функциональности.

Анализ литературных источников показывает, что практически отсутствует информация о разделении полимеров по изомерному составу. В настоящей работе методами двухдетекторной ЭЖХ и обращенно-фазовой АЖХ исследованы продукты процесса аминирования $\alpha$-гексена. Как известно, в указанном процессе миграция протонов к разным атомам углерода приводит к образованию различных изомеров $\alpha$ гексена [23]. Можно полагать, что образующиеся низкомолекулярные олигомеры (теломеры) могут также обладать разной изомерной структурой. На фоне изменения ММР изучение механизма процесса аминирования, в том числе и структуры образования низкомолекулярных олигомеров в данном процессе представляет интерес.

Цель настоящей работы состоит в изучении структурной неоднородности продуктов аминирования $\alpha$-гексена в синтезированной окислительновосстановительной системе $\mathrm{NH}_{2} \mathrm{OH} \cdot \mathrm{HCl}-\mathrm{TiCl}_{3}$ и выявлении методами двухдетекторной ЭЖХ и обращенно-фазовой АЖХ возможных типов разделения по химическому составу продуктов.

\section{Эксперимент}

Хроматографическое исследование осуществлено методом ВЭЖХ с применением обращенно-фазовой АЖХ и ЭЖХ [24, 25]. Использован высокоэффективный жидкостной хроматограф чешской фирмы Kovo, с двумя колонками с размером

Бекташи Н.Р. / Сорбционные и хроматографические процессы. 2018. Т. 18. № 1 
$3.3 \times 150$ мм, заполненными адсорбентами «Separon SGX C18» (АЖX режим) и «Separon $S G X »$ с диаметром пор $100 \AA$ (ЭЖХ режим). Размер частиц составлял 7 мкм. Были выбраны двухдетекторные варианты указанных методов с использованием УФспектрофотометрического ( $\lambda=254$ нм) и рефрактометрического детекторов. Элюенты: метанол+вода $(75: 25$ об. \%) и диметилформамид соответственно. Скорость их подачи $0,3 \mathrm{~cm}^{3} /$ мин. $\mathrm{T}=20-25^{\circ} \mathrm{C}$.

ММР и ММ продуктов аминирования гексена установлены по градуировочной зависимости между $\lg M$ и $V_{R}$, полученной в ЭЖХ режиме с применением монои диаминогексана и полиэтиленгликолевых стандартов, а также с применением градуировочной зависимости представленной в работе [21]. Градуировочная зависимость получена также в АЖХ режиме, при использовании полиэтиленгликолевых стандартов в диапазоне ММ 400-1500 и исследуемых моно- и диаминоалканов. Линейный участок градуировочной кривой описываются уравнением $V_{R}=C_{1}-C_{2} \lg M$, где $C_{I}=3.77, C_{2}=0.52$ (эксклюзионный режим) и $C_{I}=6.5, C_{2}=1.75$ (адсорбционный режим). Здесь $\mathrm{C}_{1}$ - отрезок, отсекаемый на оси ординат продолжением линейного участка, a $\mathrm{C}_{2}$ - тангенс угла его наклона к оси ординат. Величину $\mathrm{C}_{2}$ называют разделительной емкостью колонки, ее выражают числом миллилитров растворителя, приходящегося на один порядок изменения ММ, а М - логарифмическое значение $M_{n}$ градуировочных стандартов.

Среднечисленная функциональность по двойным связям вычислена по фор-

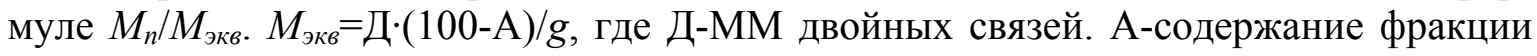
не содержащей двойных связей, g- содержание двойных связей. При этом содержание двойных связей определено методом спектрального озонирования на приборе АДС-4.

ИК-спектральный анализ образцов осуществлен на спектрофотометре «Specord M-80» в области волновых чисел 400-3200 $\mathrm{cm}^{-1}$. Спектры ЯМР ${ }^{1}$ Н определяли на приборе Varian XL-200 ДМCO-d6 (рабочая частота 200 МГц), внутренный стандарт тетраметилсилан. Синтез аминогексенов осуществлен по методике [23].

\section{Обсуждение результатов}

Изучение свойства продуктов аминирования $\alpha$-гексена в указанных хроматографических системах показало, что полученные продукты представляют собой сложную смесь фракций, отличающихся не только по молекулярной массе (MM), a также по изомерному составу. В этом можно убедиться из данных в таблице 1 и из представленных на рис. 1 и 2 хроматограмм анализируемых продуктов, снятых методами АЖХ и ЭЖХ в двухдетекторной системе хроматографирования (рефрактометр и УФ-спектрофотометр).

Таблица. 1. Параметры ММР и фракционные составы продукта аминирования $\alpha$-АГ идентифицированные методами АЖХ и ЭЖХ

\begin{tabular}{|c|c|c|c|c|c|c|c|}
\hline \multirow{3}{*}{$\begin{array}{l}\text { Фрак- } \\
\text { ция, № }\end{array}$} & \multirow{3}{*}{ Название } & \multicolumn{6}{|c|}{$\mathrm{MMP}^{*}$} \\
\hline & & \multicolumn{2}{|c|}{ Фракция, \% } & \multicolumn{2}{|c|}{ АЖX } & \multicolumn{2}{|c|}{ ЭЖХ } \\
\hline & & АЖX & ЭЖХ & $\begin{array}{c}M_{n}, \\
\text { Г/моль }\end{array}$ & $M_{w} / M_{n}{ }^{*}$ & $\begin{array}{c}M_{n}, \\
\Gamma / \text { моль }\end{array}$ & $M_{w} / M_{n}$ \\
\hline 1 & ОГ & 5 & 4 & 794 & 1,02 & 800 & 1,03 \\
\hline 2 & $\mathrm{O \Gamma}$ & 14 & 16 & 660 & 1.03 & 670 & 1.05 \\
\hline 3 & $\mathrm{O} \Gamma$ & 6 & 8 & 478 & 1.02 & 460 & 1.02 \\
\hline 4 & Смесь ДАДД & 5 & 4 & 200 & --- & 200 & --- \\
\hline 5 & $\alpha-\mathrm{A} \Gamma$ & 70 & 68 & 100 & --- & 100 & --- \\
\hline
\end{tabular}

${ }^{*} M_{w}=M_{n} \times M_{w} / M_{n}$. 
На хроматограммах продуктов, снятых рефрактометром в обеих системах, были зафиксированы пять фракций. Исходя из результатов спектральных анализов, а также из ранее полученных нами данных по аминированию $\alpha$-олефинов [23] можно полагать, что фракция обнаруженная при $V_{R}=3 \mathrm{~cm}^{3}$ (рис. 1), по содержанию соответствует 1-аминогексану, являющемуся основным изомером моноамина гексена-1 (70\%). А фракция, выявленная при $V_{R}=2.5 \mathrm{~cm}^{3}$ (5\%), соответствует смеси изомеров диаминосоединений т.е. 5.8 и 6.7 диаминододекану (ДАДД), являющихся продуктами димеризации аминоалкильных радикалов, образуюущихся при атаке радикалов $\mathrm{NH}_{2}$ на молекулы $\alpha-$ олефинов. При этом происходит перенос протона от углеродного атома $\mathrm{C}_{1}$ к $\mathrm{C}_{2}$ и от $\mathrm{C}_{2}$ к $\mathrm{C}_{1}$ соответственно с образованием радикалов $\left[\mathrm{NH}_{2}-\mathrm{CH}_{2}-\right.$ $\left.\left.\dot{\mathrm{C}} \mathrm{H}-\left(\mathrm{CH}_{2}\right)_{3}-\mathrm{CH}_{3}\right)\right]$ и $\left.\left[\dot{\mathrm{C}} \mathrm{H}_{2}-\mathrm{CH}\left(\mathrm{NH}_{2}\right)-\left(\mathrm{CH}_{2}\right)_{3}-\mathrm{CH}_{3}\right)\right]$.

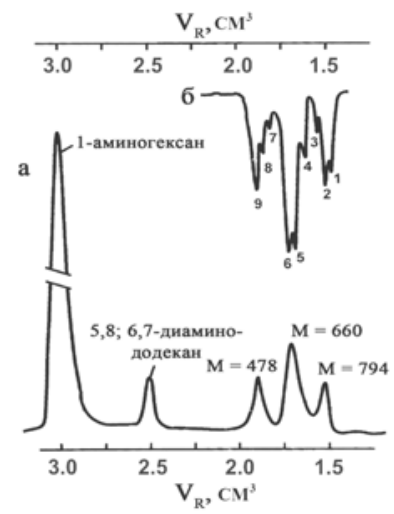

Рис. 1 Адсорбционные кривые ММР продуктов аминирования $\alpha$-гексена. Адсорбент-Separon $S G X$ C18, элюент метанол:вода $(75: 25 \%), 0.3 \mathrm{~cm}^{3} /$ мин,

$\mathrm{T}=20-25^{\circ} \mathrm{C}$. Здесь и на рис. 2 детекторы: рефрактометр $(a)$, УФ-спектрофотометр $(\lambda=254$ нм $)(б)$.

Установлено, что серия фракции, фиксируемых на хроматограмме при значениях $V_{R}=1.5,1.7$ и $1.88 \mathrm{~cm}^{3}$, соответствует теломерам с $M_{n}=794,660$ и 478 с содержанием 5, 14 и $6 \%$ соответственно (рис.1). При этом суммарная ММ теломерных фракций, общее количество которых $25 \%$, составляет $M_{n}=630$. Содержание двойных связей в их составе достигает $1.1 \%$. На основе указанных выше значений было установлено, что среднечисленная функциональность фракции теломеров по $\mathrm{C}=\mathrm{C}$ связи составляет $f_{n}=1.06$, т.е. каждая теломерная молекула содержит одну двойную связь.

Количественное соотношение фракционного состава исследуемого продукта подтверждено также двухдетекторной ЭЖХ. Как следует из рис. 2 на ЭЖХ хроматограмме того же образца, снятой рефрактометрическим детектором (кривая 1), зафиксированы фракции по ММ, соответствующие моно- и диаминосоединениям или, как указано выше, 1-аминогексану и 5,8 и 6,7 диаминододекану с содержанием соответственно 68 и 5\%. Серии зафиксированных в этом режиме сигналов четко разделяемых фракций теломеров проявляются в тримодальной форме и отличаются остротой. Как и предыдущие, эти фракции по параметрам примерно отвечают идентичным параметрам, полученным в АЖХ режиме, по ММ $\left(M_{n}=800,670,460\right)$, по содержанию $(5,14$ и $8 \%)$ а также по среднечисленной функциональности по двойным связям $\left(f_{n}=\right.$ 0.98). Установлено, что в составе исследуемого аминопродукта уменьшение полярности фракции совпадает с уменьшением их ММ и, соответственно, разделение происходит по эксклюзионному механизму. 


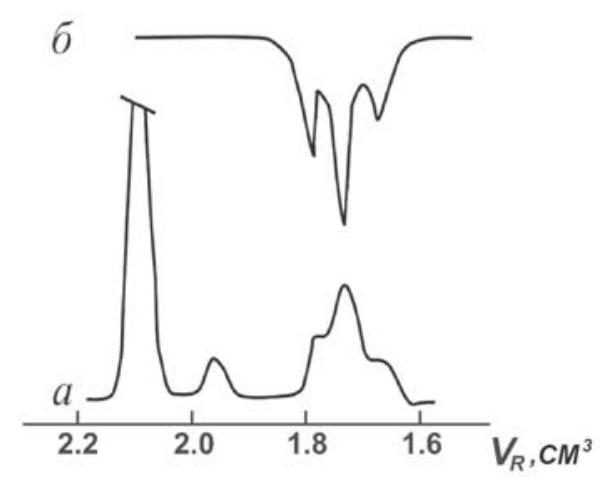

Рис. 2. Эксклюзионные кривые ММР продуктов аминирования $\alpha$-гексена. Адсорбент-Separon $S G X$, элюент ДМФА, $0.3 \mathrm{~cm}^{3} /$ мин, Т $=20-25^{\circ} \mathrm{C}$.

При УФ-детектировании в обоих вариантах хроматографической системы сигналы проявляются в начальной части хроматограммы образца, т.е. фиксируются только фракции теломеров (рис. 1 и 2, кривые б), а сигналы моно- и диаминосоединений, в отличие от рефрактометрических данных, отсутствуют. Это связано с наличием в составе теломеров концевых хромофорных $\mathrm{C}=\mathrm{C}$ связей, хорошо поглощающих в УФ-области. Если при рефрактометрическом детектировании разделение наблюдается только по ММ, то в случае УФ-детектора в режиме АЖХ разделение фракции фиксируется и по изомерному составу. Об этом свидетельствует мультиплетный характер сигналов фракции теломеров (рис. 1, кривая б). Как следует из рисунка, в пределах одинаковой ММ $\left(V_{R}=1.5,1.7\right.$ и $\left.1.88 \mathrm{~cm}^{3}\right)$ каждая фракция характеризуется тремя максимумами, отличающимися различной интенсивностью. Первые два максимума можно отнести к более полярным $\alpha$ - и $\beta$-аминоолигогексенам (максимумы $1,2,4,5,7$ и 8), образующихся при 1,2 и 2,1 миграции водорода, а третий менее полярный изомер соответствует олигоаминогексену, образующемуся при миграции водорода либо от второго к третьему, либо к четвертому углеродному атому (максимумы 3, 6 и 9).

Таким образом, по мультиплетности сигналов можно сделать выводы о том, что в исследуемом процессе при миграции протонов к разным атомам углеродов происходит образование радикалов с разной реакционной способностью, вследствие чего соответственно образуются олигомеры с разными ММ. Структуры получаемых олигомеров можно представит в следующем виде:

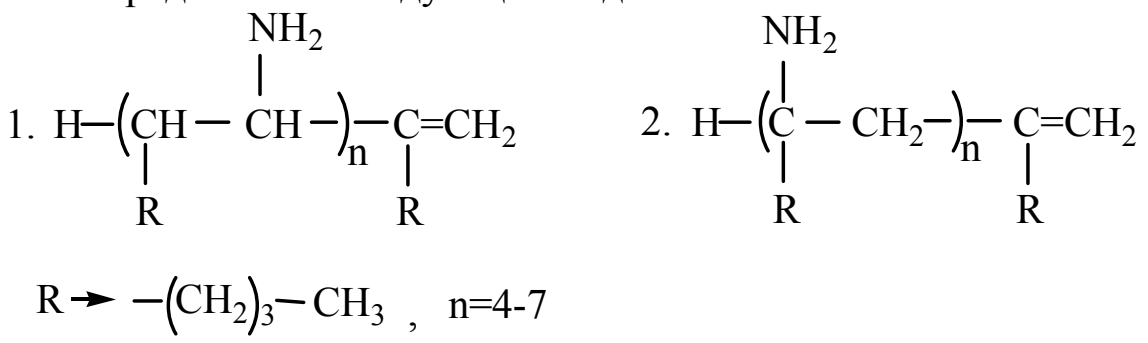

Структура продуктов аминирования изучена и подтверждена методами ИК и ЯМР спектроскопии. В ИК-спектре присутствуют интенсивные полосы поглощения в области $1379 \mathrm{~cm}^{-1}$ и $1469 \mathrm{~cm}^{-1}$, характерные для групп $\mathrm{CH}_{3}$ и $\mathrm{CH}_{2}$, а также полоса 720-740 см ${ }^{-1}$, соответствующая деформационным С-Н колебаниям в неразветвленных цепях - $\left(\mathrm{CH}_{2}\right)_{n}$. Слабая полоса поглощения, обнаруживаемая в области $966 \mathrm{~cm}^{-1}$, указывает на присутствие малого количества замещенной двойной связи, находящейся на конце теломерной цепи $-\mathrm{RC}=\mathrm{CH}_{2}$. Благодаря высокому содержанию моноамина в составе продукта в области $1600 \mathrm{~cm}^{-1}$ зафиксированы сильные полосы по- 
глощения, соответствующие первичной аминной группе $\mathrm{NH}_{2}$. Полосы характерных для групп $\mathrm{NH}_{2}$ валентных колебаний наблюдаются также при 3400- $3200 \mathrm{~cm}^{-1}$.

Спектры ЯМР ${ }^{1} \mathrm{H}$ подтвердили ИК-спектроскопические данные продуктов аминирования. Четыре протона с $\delta=1.03$ м.д. соответствовали аминным протонам группы $\left(\mathrm{NH}_{2}\right)_{2}$. При разбавлении сигнал от аминных протонов смещался в область сильных полей $(\delta=1.02)$, что также свидетельствует о четкости отнесения аминогруппы. Уширенный сигнал из-за влияния атома азота при $\delta=2.5$ м.д. соответствует по интегральной интенсивности двум метильным протонам при атоме азота, химический сдвиг которых согласуется с литературными данными [26]. Наблюдаются также сигналы при 3.55 м.д. (триплет, 2Н), 1.75 (мультиплет, 2Н), 1.45 (мультиплет, 2H) и 0.92 (триплет, 3Н). Это сигналы н-бутильного радикала, т.e. R в формуле (1).

В спектре ${ }^{1} \mathrm{H}$ ЯМР соединения в области слабых полей наблюдаются уширенные сигналы при 4.69 м.д. и 4.66 м.д. (2Н). Такая картина характерна для терминальных протонов двойной связи $=\mathrm{CH}_{2}$. Наличие в молекулах димеров длинных алкильных цепей указывает сигналы 14.1, 22.7 и 29.7.

\section{Заключение}

Методом двухдетекторной ЭЖХ установлено, что в составе продуктов аминирования $\alpha$-гексена наряду с индивидуальными аминоалканами имеет место олигомеризация $\alpha$-гексена приводящая к возникновению трех фракций с ММ в интервале 460-800. Метод обращенно-фазовой АЖХ позволил выявить в составе продуктов разделение по изомерному составу, при этом каждая теломерная фракция состоит из смеси трех изомеров, разделение которых происходит в порядке уменьшения их полярности. Показано соответствие первых двух изомеров более полярным $\alpha$ - и $\beta$ - олигоаминогексенам, образующихся при 1,2 и 2,1 миграциях водорода, а третий менее полярный изомер соответствует олигоаминогексену, образующемуся при миграции водорода либо от второго к третьему, либо к четвертому углеродному атому.

\section{Список литературы}

1. Рафиков С. Р., Павлова С. А., Твердохлебова И. И. Методы определения молекулярных весов и полидисперсности высокомолекулярных соединений. М. Изд-во Академии наук СССР. 1963.336 c.

2. Современное состояние жидкостной хроматографии / Под ред. Д. Киркленда. М. Мир. 1974. 325 с.

3. Жидкостная колоночная хроматография, под ред. 3. Дейла, К. Мацека, Я. Янака, пер. с англ. Т. 1-3. М. Мир. 1978. 428 с.

4. Экстракционная хроматография, под ред. Т. Браун и др., пер. с англ., М. Мир. 1978. $627 \mathrm{c}$.

5. Batzer H., Zahir S.A. //Journal of Applied polymer science, 1975, Vol. 19, pp. 585-600, 601-607, 609-617.

6. Dondos A., Benoit H. // Die Makromolekulare Chemie, 1974, Vol. 175. pp. 1659-1663.

7. Servotte A., De Bruil R. // Die Makromolekulare Chemie, 1975 Vol. 176. pp. 203-212.
8. Энтелис С.Г. // Соросовский образовательный журнал 1996. № 7. С. 59-66.

9. Энтелис С.Г., Евреинов В.В., Кузаев А.И. Реакционноспособные олигомеры. М. Химия. 1985. $304 \mathrm{c.}$

10. Благодатских И. В. Дисс. док. хим. наук. М. 2008. 21 с.

11. Роздина И.Г., Филатова Н.Н., А. В. Горшков А.В., Евреинов В.В. // Высокомолек. соед. Серия А. 2013. Т. 55. № 1. С. 62-65.

12. Роздина И.Г., Филатова Н.Н., А. В. Горшков А.В., Евреинов В.В. // Высокомолек. соед. Серия А. 2013. Т. 55. № 6. С. $764-$ 772.

13. Горшков А.В., Горшков М.В., Роздина И. Г., Тарасова И.А. и др. // Высокомолек. соед. Серия А. 2010. Т. 52. № 3. С. 478-486.

14. Горшков А.В., Евреинов В.В., Тарасова И.А., Горшков М.В. // Высокомолек. соед. Серия Б. 2007. Т. 49. № 4. С. 732-749. 
15. Bektashi N.R., Alieva R. Dzalilov R.A., Ragimov A.V. // Polymer Science, Ser. B. 2000. Vol. 42. No 9-10. pp. 276.

16. Crompton T.R. // Polymer referans book, RapraTechnology Ltd. United Kingdom. 2006. pp. 273.

17. Бекташи Н.Р., Джафаров В.Д., Чалябиев Ч.А., Азадалиева Г.Н., Кулибекова Л.Н. // Аз.хим журн. 2001. № 3. С. 52.

18. Bektashi N.R., Djafarov V.C., Azadaliyeva G.N., Efendiyev A.A. İnternational Workshop - Conference, HPLC procedures for seperation of macromolecules. Slovakia. Bratislava. 2001. pp. 11.

19. Гулиев С.А, Бекташи Н.Р., Шарифов Г.С., Эфендиев А.А. // Аз.хим журн. 2002. № 4. C. 35 .

20. Bektashi N.R., Dzafarov V.A. // Polymer Science, Ser. A. C/C of vysokomolekuliarnye soedineniya. 2004. Vol. 46. pp.1239.

\section{References}

1. Rafikov S.R., Pavlova S.A., Tverdokhlebova I.I., Metody opredeleniya molekulyarnykh vesov i polidispersnosti vysokomolekulyarnykh soyedineniy. M., Izd-vo Akademii Nauk SSSR, 1963, 336 p.

2. Sovremennoe sostoyaniye jidkostnoy khromatografii, Ed. D. Kirkland, M., Mir, 1974, 325 p.

3. Jidkostnaya kolonochnaya khromatografiya, ed. Z. Dale, K. Matzek, J. Yanaka, per. with English., t. 1-3, M., Mir, 1978, 428 p.

4. Ekstraktzionnaya khromatografiya, ed. T. Brown et al., Trans. with English., M., Mir, 1978, $627 \mathrm{p}$.

5. Batzer H., Zahir S.A., Journal of Applied polymer science, 1975, Vol. 19, pp. 585-600, 601-607, 609-617.

6. Dondos A., Benoit H., Die Makromolekulare Chemie, 1974, Vol. 175, pp. 1659-1663.

7. Servotte A., De Bruil R., Die Makromolekulare Chemie, 1975, Vol. 176, pp. 203-212.

8. Entelis S.G., Soros Educational J., 1996, No 7, pp. 59-66.

9. Entelis SG, Evreinov V.V., Kuzayev A.I., Reaksionnosposobnye oligomery. Moscow, Chemistry, 1985, $304 \mathrm{p}$.

10. Blagodatskikh I.V. Diss. doc. chem. sciences. M., 2008, 21 p.

11. Rozdina I.G., Filatova N.N., Gorshkov A.V., Evreinov V.V., Journal of High
21. Bektashi N.R, Mustafaev A.M, Guseinov I.A, and. Dzafarov V.D. // Russian J. of Applied Chemistry. 2011. Vol. 84. No 7. pp. 1281.

22. Бекташи Н.Р. // «Найновите научни постижения-2013», България. София. 2013. № 18. C. 61.

23. Асланов Т. А, Мустафаев Р.И. // Нефтехимия. 1988. Т. 27. № 4. С. 541.

24. Veliyev M.G., Salmanov M.A., Bektashi N.R., Aliyeva S.R. et al. // Analyt. Chem. 2013. Vol. 1. No 4. pp. 7-11.

25. Стыскин Е.Л., Ициксон Л.Б, Брауде Е.Б. Практическая высокоэффективная жидкостная хроматография. М. Химия. 1986. 313 c.

26. Дероум Э. Современные методы ЯМР для химических исследований. М. Мир. $1992.403 \mathrm{c}$.

Molecular Chemistry Series A, 2013, Vol. 55, No 1, pp. 62-65.

12. Rozdina I.G., Filatova N.N., Gorshkov A.V., Evreinov V.V., Journal of High Molecular Chemistry Series A, 2013, Vol. 55, No 6, pp. 764-772.

13. Gorshkov A.V., Gorshkov M.V., Rozdina I.G., Tarasova I.A. et al., Journal of High Molecular Chemistry Series A, 2010, Vol. 52, No 3, pp. 478-486.

14. Gorshkov A.V., Evreinov V.V., Tarasova I.A, Gorshkov M.V., Journal of High Molecular Chemistry. Series B, 2007, Vol. 49, No 4, pp. 732-749.

15. Bektashi N.R., Alieva R., Dzalilov R.A., Ragimov A.V., Polymer Science. Ser. B, 2000, Vol. 42. No 9-10, pp. 276-281.

16. Crompton T.R. Polymer referans book, United Kingdom. Rapra Technology Ltd., 2006, pp. 273-278.

17. Bektashi N.R., Dzhafarov V.D., Chalyabiev Ch.A., Azadalieva G.N. et al., Az.khim jur., 2001, No 3, pp. 52-56.

18. Bektashi N.R., Djafarov V.C., Azadaliyeva G.N., Efendiyev A.A. İnternational Workshop - Conference, HPLC procedures for seperation of macromolecules, Slovakia, Bratislava, 200, pp.11-12.

19. Guliev S.A., Bektashi N.R., Sharifov G.S., Efendiev A.A., Az.khim jur., 2002, No 4, pp. 35-39. 
20. Bektashi N.R., Dzafarov V.A., Polymer Science, Ser. A. of vysokomolekuliarnye soedineniya, 2004, Vol. 46, pp.1239-1244.

21. Bektashi N.R, Mustafaev A.M, Guseinov İ.A, and. Dzafarov V.D., Russian J. of Applied Chemistry, 2011, Vol. 84, No 7, pp.1281-1285.

22. Bektashi N.R. "Recent scientific achievements -2013", IX Interdisciplinary and practical conference Bulgaria, Sofia, 2013. No 18 , pp. 61-67.

Бекташи Назим Рауф оглы - к.х.н., доцент лаборатории физико-химического анализа, Институт Полимерных Материалов Национальной Академии наук Азербайджана, Тел.моб.(+99470 $4558820)$
23. Aslanov T.A, Mustafayev R.I., Petrochemistry, 1988, Vol. 27, No 4, pp. 541546.

24. Veliyev M.G., Salmanov M.A., Bektashi N.R., Aliyeva S.R. et al., J. Analyt. Chem., 2013, Vol. 1, No 2, pp. 7-11.

25. Styskin EL, Itzikson LB, Braude E.B. Prakticheskaya vysokoeffektivnaya jidkostnaya khromatografiya, M., Chemistry, 1986, 313 p.

26. Deroom E. Sovremennye metody YMR dlya khimicheskikh issledovaniy, M., Mir, 1992, 403p.

Bektashi Nazim Rauf oglu - Associate Professor of the Laboratory of Physical-Chemical Analysis, Institute of Polymer Materials National Academy of Sciences of Azerbaijan, nazimbektash@gmail.com 